\title{
Education: The Key to Curb HIV and AIDS Epidemic
}

\author{
Bhatta DN, ${ }^{1}$ Aryal UR, ${ }^{2}$ Khanal K ${ }^{3}$
}

${ }^{1}$ Department of Public Health

Pokhara University, Nobel College

Sinamangal, Kathmandu

${ }^{2}$ Department of Community Medicine

Kathmandu Medical College

Sinamangal, Kathmandu

${ }^{3}$ Department of Community Medicine

Kathmandu University School of Medical Sciences

Dhulikhel, Nepal

Corresponding Author

\section{ABSTRACT}

Overwhelming impact has been established among different aspects and burden of incurable HIV and AIDS is increasing day-by-day globally. The aim of this article is to discuss the potential benefits and strengths of an education system in the absence of remedy and help to develop future strategies. Education has great impact on HIV and AIDS and vice-versa. An education plays a vital role to curb the transmission of HIV and AIDS thorough capacity building, provides information, reduces vulnerability, empowerment, improve life skill, maintain equity, reduce dependence, stigma, and discrimination, where are abundance foundations for HIV infection. HIV and AIDS has role for devastation of education system and level which has great impact on productivity, economic growth, demand, supply and daily life of human being. Low and middle income countries needs to be improve recording and reporting systems related to impact of HIV and AIDS on education. By analyzing preceding evidences, policy makers or governance feels to reformulate policies relating to education and health. Evidence based policy and program will be more useful to address distressing squall of epidemic.

Dharma Nand Bhatta

Pokhara University, Nobel College

\section{KEY WORDS}

Education, hope, impact HIV and AIDS

Department of Public Health

Sinamangal, Kathmandul

E-Mail:dnbhatta@yahoo.com

Citation

Bhatta DN, Aryal UR, Khanal K. Education: The Key to Curb HIV and AIDS Epidemic. Kathmandu Univ Med J 2013;42(2):158-161.

\section{INTRODUCTION}

Nearly more than three decades where lagoon of medical treatment, HIV and AIDS has developed distressing challenges around the world. At present, only antiretroviral therapy is for supportive treatment and waiting for completely curable medicine and vaccine to control the disease. Burden of the HIV vary between countries to countries and regions, where worldwide prevalence of HIV among adults aged 15-49 years is $0.8 \%$ at the end of 2011. Sub-Saharan Africa has higher prevalence of HIV infection which is nearly 25 times higher than in Asia. ${ }^{1}$ Caribbean and Eastern Europe and Central Asia are the second higher prevalent regions of HIV. Worldwide, various efforts marked declining in new infection of HIV among adults and child population. Antiretroviral therapy has significant impact on declining of AIDS related mortality. ${ }^{1}$
Globally, the major cause of HIV transmission is unsafe sexual intercourse (incompatible and low condom use) with infected person. Besides it, sharing infected needles for injecting drug use, mother-to-child transmission and infected blood and blood products are also most important mode of transmission in different countries. ${ }^{2}$

HIV transmission through various means can be reduced by enhancing HIV and AIDS education, and after education system of the country has improve its quality and contribution. Worldwide, by far absence of HIV treatment and other specific interventions education offers a significant gauge of defense and prevention against HIV and AIDS by guarantying to fair, excellence and complimentary education to all children. ${ }^{3}$ According to Global Campaign 
for Education (GCE), worldwide primary education would significantly prevent seven million new HIV infections in a decade. ${ }^{4}$ Admirable education system can generate caring and defending environment to the community for sustainable impact on dropping susceptibility and intensified risk with empowerment. This can be enhanced by making economically dynamic, ensuring to autonomous preferences and safety, enable to develop morals and providing knowledge and skills to formulate healthy decisions about their personal as well as social lives. , $^{6}$

With especial focus on the worldwide education system, some forthcoming situation for a social segment can be garner from an examination of the effects of HIV and AIDS on education. ${ }^{7}$ Globally, in the absence of a cure and vaccine, HIV and AIDS affect and weaken quality of life among family and community; reduced personal, regional and national production; creates major problems in health system and health care practices; pressures on excellent governance and human protection; effects on capability of societies, plans and programs. ${ }^{1,6}$ It raises destruction of families and communities to keep away from expectation and future among all over the world. HIV/AIDS epidemic also impact on education system where it can reduce technical, financial as well as human resources. Due to the economic difficulties, fear of stigma, discrimination and AIDS related death reduces the demand for education, withdrawn from school. It affects the sustainability of quality education and absenteeism of quality teacher. ${ }^{1,3}$

\section{DISCUSSION}

HIV and AIDS have pronounced impact on education

First, HIV and AIDS influence the demand for education. HIV and AIDS epidemic will reduce numbers of children to educate which might be due to lower fertility among infected surviving adults and higher mortality. Increasing AIDS orphans, poverty, stigma, discrimination and girl child used care for sick family members affects the demand for education. In Guatemala, studies have shown that more than a third of children orphaned by AIDS drop out of school. ${ }^{8}$ It was estimated that around 500,000 girls and 400,000 boys of primary school age were not attending school in Nepal with or without HIV/AIDS. ${ }^{9}$ Strategies to capacity building of teacher and educational institutions may urgently require for effective role of quality education on HIV and AIDS.

Second, the supply of education, where most of the low and middle income countries have not accurate data on HIV and AIDS related deaths and prevalence among students and teachers. However published literatures from few countries supported to point out an increased teacher mortality rate in the presence of HIV and AIDS. Nonetheless there is some argument concerning the impact among lower and higher epidemic countries. Illness and death could increase the teachers' attrition and absenteeism rate. ${ }^{10,11}$ Supply and demand phenomena reduce the education quality and countries must have an alternative priority plans for replacing skilled professional and providing ART for teachers. ${ }^{12}$

Third, the quality of education depends upon various things like right of entry, exposure, quality control, human and other resources. Investment on education might be less from HIV infected family, parents and community. Stigma, discrimination and low motivation might affect the teachers' quality. In addition, the loss of policy makers from nation, provinces and universities will affect the quality of planning, training and support. ${ }^{13}$ In this circumstance, strong united community and non-formal education might have vital role to address this issue.

Fourth, the specific costs of HIV and AIDS to the education sector which will be new beginning approach for higher epidemic countries. Frequent turnover of teachers, absenteeism, and long term sick leave provision can inflict a major problem on education budgets among the poor resource setting countries. Previous literature revealed that the hypothetical cost of recruiting and development of teacher to restore those lost to AIDS is expected to attain US\$233 million by 2016 and unproven cost that increased the total 1998/99 budget for all supplies and services. ${ }^{3,7,14}$ In the other hand opportunity costs will in high demand which have to great consider with high skilled personnel and human resources. In addition, other macroeconomic consequence of children is not to access of education. There is the major problem of new recruitment which rise economic issue on demand side cost. New expenditure, vulnerability of children will estimate the assumption of impact of HIV and AIDS on education supply and demand. ${ }^{6}$

Above four are the major impacts of HIV and AIDS on education, albeit there is numerous other affects which were usually addressed by previous literatures. ${ }^{7}$ It will affect the accessibility of resources for education which might come across with economic disruption and reduced work productivity, which makes unable to contribute in self-help activities in schools. HIV and AIDS affects the prospective clients of education due to the increased orphans, family destruction, poverty, increased street children which will also be common fundamental dilemma among the civil war and conflict leaning countries with frequent demographic changes. HIV and AIDS will basically modify the education process in low and middle income developing countries. Disbelieve among teacher, individual and community, fear of future, stigma, sexual abuse and exploitation will alter the education process. Life skill, sexuality, gender equity, and empowerment related contents might be included in the contents of curriculum which will address the HIV and AIDS impact. HIV/AIDS affects the responsibility of education, union of school, planning and management of education system, external support to development of education. Education policy of the countries needs to be enhancing for capacity building according to various contexts. In a positive layer, the World Bank has recommended that 
the support of capacity building to the countries which is mainly exaggerated by AIDS. ${ }^{15}$

Why education matters: Education protect against HIV and AIDS infection

Global and national economy or productivity, coping extreme poverty, quality of life, social activities relied competitive on quality education. Sound macro and micro economic policies, educated people and workforce are fundamental to national health development. We also know that medicines or vaccine exist for HIV and AIDS, albeit education creates expectations. It suggests a gauge of protection; reduce vulnerability against HIV/AIDS. Death is fastening with after HIV and AIDS however education will decline to give way of suffering and is make moralize, happy and flexible.

Literature showed that the specific interventions (in different level a. while as yet there is no infection $b$. when infection has occurred c. when AIDS has brought death) have significant measure of protection against HIV and AIDS. ${ }^{16}$ The Global Campaign for Education (GCE) has estimated that the each year 700,000 new HIV infection can reduced by providing widespread primary education. ${ }^{17}$ HIV vaccine and remedies needs to be search rigorously, until through education we can immunize them, we can furnish them intellectually, affectively, morally with providing information and skills and rising principles that creates healthy decisions about their lives; and giving them the likelihood to create sovereign alternative and to be economically creative. ${ }^{6,7}$

Education can do work with the distinct principles where these are short and medium term (there is no contamination); has possible to provide adequate knowledge and skills for self protection, positive value system, promotes healthy behavior and improve capacity. When infection has happened; it has possible to strengthen the coping ability, motivating to caring others, reduce stigma, discrimination, shame and stand up for human rights. When death has occurred; it has strengthen the coping with sorrow and loss, help in empower of family members and support for personal rights. In the long term; it has possible to make easiness conditions, reduce poverty, gender discrimination, bullying, susceptibility, orphans or streetism, dependence, increase empower and capacity building. ${ }^{6}$

Education can cover wide areas children, young people and even who are not in school

Most commonly the HIV epidemic relies on the teenage and young age group people. Majority of this age group children spend time in school. This period is transitional phase for personal development and education can enhance their behavior, skill, knowledge, and attitude. Previous literature revealed that the education has vital role to support for those who are HIV infected and affected. ${ }^{18}$ Education ensures access for genuine and pertinent learning for those who are out of school. It offer universal learning opportunities and access to education through community involvement. Significant numbers of children are far from school and dropping out and this trend will increase in future after HIV and AIDS epidemic.

Education can decrease vulnerability, stigma, discrimination and rise human right issues

Education empower the young women, develop the capacity to provide information regarding HIV prevention, it can improve the economic condition and make aware them about sexual network and affecting society. ${ }^{19}$ Intervention of HIV and AIDS has established the possible of education to bring changes in attitudes towards people living with HIV and AIDS. ${ }^{20}$ This is really significant to reduce stigma and discrimination. It makes prevention through education very difficult. It is a key way to break the silence and move the response forward. Human rights need to widen their treatment, the right to work, and the right to the highest attainable standard of physical and mental health. ${ }^{21}$

Higher education has greater impacts and benefits on HIVrelated knowledge, development of life skills and behavior

Education help to develop life kills which furnish them for positive social behavior and sex and HIV education intervention enhance knowledge, skills and change attitude of sexual risk behaviors among sexually active. ${ }^{22,23}$ The UNAIDS review of research highlighted the importance of the skill of interpreting the conflicting messages that come from adult role models, television, other media and advertisements. Literatures have shown that girl who have lower or primary level education have greater risk of HIV infection and unsafe sex practice than who have secondary education. ${ }^{19}$ Starting from primary level of education with integrated HIV and AIDS and sexual education might enhance the process of identifying the valuable opening it to others. This can enhance the sexual debut and promote condom utilization, delaying sex, reduce sex partner, treatment, reduce risky behavior and promiscuity.

Education provides care, counseling, sympathy and costeffective means of HIV prevention

Vital life-skills in the HIV and AIDS include sympathy and harmony towards infected people and need to care for family living with HIV and AIDS. These points are essential to the school children for more assistance, counseling and psychological support. Access of quality education can evade deteriorating health system, social and economic costs linked with growing HIV and AIDS prevalence and impact. ${ }^{6}$ Linking up people with psycho-social support, supporting activities, provide like skill knowledge, formulate and implement the policy can play a crucial role. 


\section{CONCLUSIONS}

This is a vital time to commit and central agenda to make changes of HIV and AIDS situation with bring vivid expectation to the people of the world, which is really different with or without AIDS. Over a period of more than thirty years without shots and remedy, education is the only efficient and cost effective choice. Education is an imperative dynamic in the control and management of HIV and is the only remedy and expectations for the pandemic. Education vaccine will give some gauge of protection along with high risk milieu. ${ }^{12} \mathrm{All}$ the developing countries should develop strategies to cope the storm of HIV and AIDS in the absence of medical remedies. Education system must provide friendly, secure, equity environment which will help to reach zero level stigma and discrimination. Authorities should develop the strategies for giving correct information to all; mobilize and maximize utilization of

\section{REFERENCES}

1. UNAIDS. Report on the Global AIDS Epidemic 2012. [Accessed online 3 June 2013]. http://www.unaids.org/en/media/unaids/contentassets/ documents/epidemiology/2012/gr2012/20121120_UNAIDS_Global_ Report_2012_en.pdf.

2. UNAIDS. Report on the Global Epidemic. Chapter Six (Comprehensive HIV Prevention), Geneva, UNAIDS 2006. [Accessed online 14 May 2013].http://data.unaids.org/pub/GlobalReport/2006/2006_GR_ CH06_en.pdf.

3. Kelly MJ. The potential contribution of schooling in rolling back HIV and AIDS. Commonwealth Youth Development, University of South Africa 2006.

4. Global Campaign for Education (GCE). Learning to Survive: How Education for All Would Save Millions of Young People from HIV/AIDS. London, GCE, 2004. [Accessed online 20 May 2013] http://www. campaignforeducation.org/resources.

5. Hogan D. Cost effective analysis of strategies to combat HIV/AIDS in developing countries. British Medical Journal 2005; 331: 1431-1437.

6. World Bank. Education and HIV/AIDS: A Window of Hope. Washington, DC, World Bank, 2002. [Accessed online 5 June 2013]. http://wwwwds.worldbank.org/external/default/WDSContentServer/WDSP/ IB/2002/05/14/000094946_02043004023371/Rendered/PDF/ multiopage.pdf.

7. M.J. Kelly. 'What HIV/AIDS Can Do to Education, and What Education Can Do to HIV/AIDS', presented to the Sub-Saharan Africa Conference of Education for All. 2000 Johannesburg; Dec 1999: 6-10.

8. Fasokun T. HIV/AIDS as a Depleting Factor in Widening Access to Education; In: Oduaran A, Bhola H. (eds). Widening Access to Education As Social Justice. Netherlands, Springer Books, 2006.

9. Friedrich H. Nepal: trends in primary education, 1980-2004: International Education Statistic; 2007.

10. UNESCO. 2008, EFA Global Monitoring Report - Education for All by 2015, Will We Make It? Paris, UNESCO, 2007. [Accessed online 4 June 2013]. http://unesdoc.unesco.org/images/0015/001547/154743e. pdf.

11. Grant KB, Gorgens M and Kinghorn A. Mitigating the Impact of HIV on Service Providers: What Has Been Attempted, What Is Working, What Has Not Worked, Where and Why? A study commissioned by DfID Service Delivery Team in collaboration with USAID, 2004.

12. Kelly MJ. The HIV/AIDS Challenge to Education: Educational Planning and Management in a World with AIDS: Training Materials. Paris, UNESCO/IIEP, 2006. [Accessed online 14 June 2013]. http://www.iiep. unesco.org/index. php?id=110. limited resources, promote innovations; interventions, promote successful approaches to control it. Low and middle income countries needs to be improve recording and reporting systems related to impact of HIV and AIDS on education. Develop the curriculum with new context and started from primary level to give contents of reproductive health. Educate through varieties of systems, for instance non-formal education, formal education, community based education, and distance learning with different medium. Formulate the plan for coping and psychological harassment, cross-sectoral, inter-sectoral and intrasectoral collaboration for financial uphill. Reformulate the policies that address HIV and AIDS, in which included sector wide approaches, collaborative funding which will reduce the treatment cost, gender responsive curricula, holistic and evidence based approaches, responsibilities of stakeholders, inclusive classes for HIV infected children with non-infective children without precincts.

13. UNAIDS Inter-Agency Task Team on Education. Toolkit for Mainstreaming HIV and AIDS in the Education Sector: Guidelines for Development Cooperation Agencies, 2008. [Accessed online 25 May 2013]. http://unesdoc.unesco.org/images/0015/001566/156673E. pdf.

14. UNAIDS. “AIDS Epidemic Update: December 2000." Geneva.

15. World Bank Report. The Impact of AIDS on Capacity Building: The Partnership for Capacity Building in Africa. Africa Region, the World Bank. Washington, DC: The World Bank; 1999.p21.

16. Kelly MJ. The Potential Contribution of Schooling in Rolling Back HIV and AIDS. Commonwealth Youth Development, University of South Africa, 2006

17. Global Campaign for Education (GCE). Learning to Survive: How Education for All Would Save Millions of Young People from HIV/ AIDS. London, 2004. [Accessed online 24 May 2013]. http://www. campaignforeducation.org/resources.

18. UNESCO. EDUCAIDS Technical Briefs: Towards a Comprehensive Education Sector Response. HIV and AIDS Education for Out-of-School Young People, Paris, 2008. [Accessed online 4 June 2013]. http:// unesdoc.unesco.org/images/0015/001584/158436e.pdf.

19. Hargreaves J. and Boler T. Girl Power - The Impact of Girls' Education on HIV and Sexual Behaviour. London, ActionAid, 2006. [Accessed online 1 June 2013]. http://www.actionaid.org.uk/doc_lib/girl_ power_2006.pdf.

20. Gallant M. and Maticka-Tyndale E. School-based HIV Prevention Programmes for African Youth. Social Science and Medicine 2004; 58 : 1337-1351.

21. UNAIDS. HIV/AIDS and Human Rights. International Guidelines. Geneva: UNAIDS; 1998.

22. Paul-Ebhohimhen VA. Poobalan A. and van Teijlingen ER. A Systematic Review of School-based Sexual Health Interventions to Prevent STI/ HIV in sub-Saharan Africa. BMC Public Health, 2008; 8: 4. [Accessed online 24 May 2013]. http://www.biomedcentral.com/content/ pdf/1471-2458-8-4.pdf.

23. Kirby D. Obasi A. Laris B. The Effectiveness of Sex Education and HIV Education Interventions in Schools in Developing Countries in Ross D. et al. (eds) Preventing HIV in Young People: A Systematic Review of the Evidence from Developing Countries. Geneva, WHO and UNAIDS Inter-Agency Task Team (IATT) on Young People, 2006. 